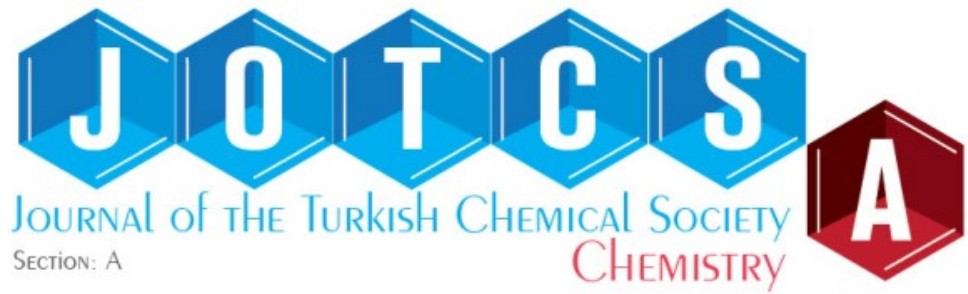

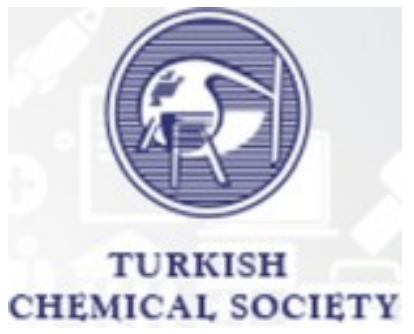

\title{
Stability-Indicating Liquid Chromatographic Method for the Simultaneous Determination of Rosuvastatin and Ezetimibe from Pharmaceuticals and Biological Samples
}

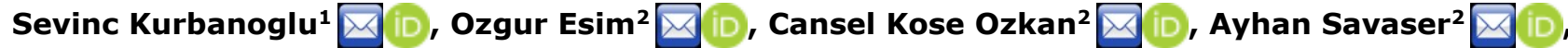 \\ Yalcin Ozkan ${ }^{2}$ D, Bengi Uslu ${ }^{1}$ D , Sibel A. Ozkan ${ }^{1 *}$ iD \\ ${ }^{1}$ Ankara University, Faculty of Pharmacy, Department of Analytical Chemistry, Tandogan, 06560 Ankara, Turkey \\ 2 University of Health Sciences, Gulhane Faculty of Pharmacy, Department of Pharmaceutical Technology, 06018, \\ Ankara, Turkey
}

\begin{abstract}
Fixed dose combinations of ezetimibe and rosuvastatin are well known to provide significantly superior efficacy to rosuvastatin alone in lowering total cholesterol, and triglyceride levels. Therefore, in this recent work, we prepared fixed dose $(10 \mathrm{mg} / 10 \mathrm{mg})$ ezetimibe and rosuvastatin tablet formulations, and a simple, selective and we established and validated rapid chromatographic method for the sensitive and simultaneous determination of rosuvastatin and ezetimibe. We performed the separation on Zorbax SB-C18 (100 mm x $4.6 \mathrm{~mm}, 3.5 \mu \mathrm{m}$ particle size) column at $30{ }^{\circ} \mathrm{C}$ with a mobile phase that has a composition as water containing $0.1 \% \mathrm{H}_{3} \mathrm{PO}_{4}$ :methanol:acetonitrile $(50: 25: 25 \mathrm{v} / \mathrm{v} / \mathrm{v})$ at $1.2 \mathrm{~mL} / \mathrm{min}$ flow rate. We further performed validation studies according to ICH guidelines. Furthermore, we exposed rosuvastatin and ezetimibe to degradation conditions. We plotted peak area vs. concentration graphs for rosuvastatin and ezetimibe and used for defining the linearity of the detector response. In this suggested method, we observed linear relationships varying from 0.05 to $50 \mu \mathrm{g} / \mathrm{mL}$ for ezetimibe concentrations and from 0.05 to $25 \mathrm{\mu g} / \mathrm{mL}$ for rosuvastatin concentrations. We found the limit of detection values for rosuvastatin and ezetimibe as 0.006 and $0.008 \mu \mathrm{g} / \mathrm{mL}$, respectively. Moreover, we further used the established method for to the analysis of ezetimibe and rosuvastatin from real spiked samples of rabbit serum.
\end{abstract}

Keywords: Rosuvastatin, Ezetimibe, Liquid Chromatography, Validation, Stability Indicating Methods.

Submitted: August 31, 2020. Accepted: October 13, 2020.

Cite this: Kurbanoglu S, Esim O, Kose Ozkan C, Savaser A, Ozkan Y, Uslu B, et al. Stability Indicating Liquid Chromatographic Method for the Simultaneous Determination of Rosuvastatin and Ezetimibe from Pharmaceuticals and Biological Samples. JOTCSA. 2020;7(3):865-74.

DOI: https://doi.org/10.18596/jotcsa.788227.

*Corresponding author. E-mail: ozkan@pharmacy.ankara.edu.tr.

\section{INTRODUCTION}

Atherosclerosis is the main aspect of coronary heart disease (CHD), the most important reason for death and the main reason of illness all over the world $(1,2)$. The main factors of risk for $\operatorname{CHD}(3,4)$ are hypercholesterolemia and higher low density lipoprotein cholesterol (LDLC) levels. Statins are generally used for lowering the cholesterol level. They inhibit the biosynthesis of cholesterol source; reduce the intracellular pools, and results in a reduction of plasma LDLC. However, an effective response cannot be obtained from a considerable fraction of hypercholesterolemic subjects, in the treatment of statin. Dose escalation and combination therapy of hypolipidemic drugs may be necessary to arrange LDLC blood levels $(5,6)$. In LDLC reduction, drug combinations are successful hence; they may have some other effects. Nevertheless, the negligible efficacy of dose increase and present combination treatments using statins are limited by tolerance and compliance (7). 
Ezetimibe, (EZE) ((3R,4S)-1-(4-fluorophenyl)-3[(3S)-3- (4-fluorophenyl)-3-hydroxyl propyl)] -4-(4hydroxy phenyl)-2-azetidinone) blocks dietary and biliary cholesterol absorption by the small intestine. Hence, US Food and Drug Administration approved EZE in 2002 for the treatment of primary hypercholesterolemia. EZE is a lipid-lowering drug active compound, can selectively prevent the intestinal absorption of cholesterol and related phytosterols (7-9). Rosuvastatin, (ROS) bis((E)-7(4-(4-flurophenyl)-6-isopropyl-2-

(methyl(methylsulfonyl)amino)pyrimidin-5-yl)

$(3 R, 5 S)$-3,5-dihydroxyhept-6-enoic acid) calcium salt is used for the treatment of hyperlipidemia inhibiting 3-hydroxyl-3-methylglutaryl coenzyme A reductase $(10,11)$. ROS is a cholesterol lowering agent, which used as precursor for cholesterol. In order to avoid cardiovascular disease, high cholesterol and associated situations ROS can be used for treatment $(12,13)$. In the market, ROS generally has dual combinations with other drug active compounds in pharmaceutical preparations such as amlodipine, fenofibric acid, salicyclic acid, olmesartan, etc. In the literature, high performance liquid chromatographic (HPLC) methods with UV detection exist for these combinations (14-17). As stated in the literature, the patients taking 5, 10, 20 , or $40 \mathrm{mg}$ rosuvastatin daily, mean plasma concentration of rosuvastatin was $1.6 \mathrm{ng} / \mathrm{mL}, 3.5$ $\mathrm{ng} / \mathrm{mL}, 6.3 \mathrm{ng} / \mathrm{mL}$ and $9.8 \mathrm{ng} / \mathrm{mL}$, respectively (18). Moreover, after a single dose of $10 \mathrm{mg}$ ezetimibe, mean ezetimibe peak plasma concentrations $\left(C_{\max }\right)$ of 3.4 to $5.5 \mathrm{ng} / \mathrm{mL}$ were obtained within 4 to 12 hours (19). Patients at risk of coronary CHD might not achieve the low-density lipoprotein cholesterol levels recommended in statin monotherapy. The usage of ROS/EZE combination therapy reduced LDL and enhanced other constituents of the lipid/lipoprotein profile more than ROS alone $(-69.8 \%$ vs $-57.1 \%, p<0.001)(6,20-22)$. in contrary, EZE does not affect the CYP enzyme system; the hydrophilic properties of ROS may reduce the need for extensive metabolism by CYP enzymes. Therefore, this overlaid pharmacokinetic effects, EZE and ROS combination is used in the therapy of LDLC (6). To identify, quantify, and separe the components, HPLC is the most widely used technique, which depends on high pressure to push solvents through the column. This method has some advantages towards other chromatographic methods such as reproducible response, high resolution, good peak shape, and high speed (23). HPLC methods are widely examined for the simultaneous determination of combined drug formulations in the biological matrix. Since routine analyses for clinical and pharmacological studies need fast and precise detection methods, in this research, determination of ROS and EZE using a stability indicated, fully validated method was provided to assay drugs in pharmaceutical dosage forms. Moreover, to demonstrate the applicability of the suggested chromatographic method, we detected EZE and ROS from prepared fixed dose combinations of EZE and ROS and spiked rabbit serum samples.

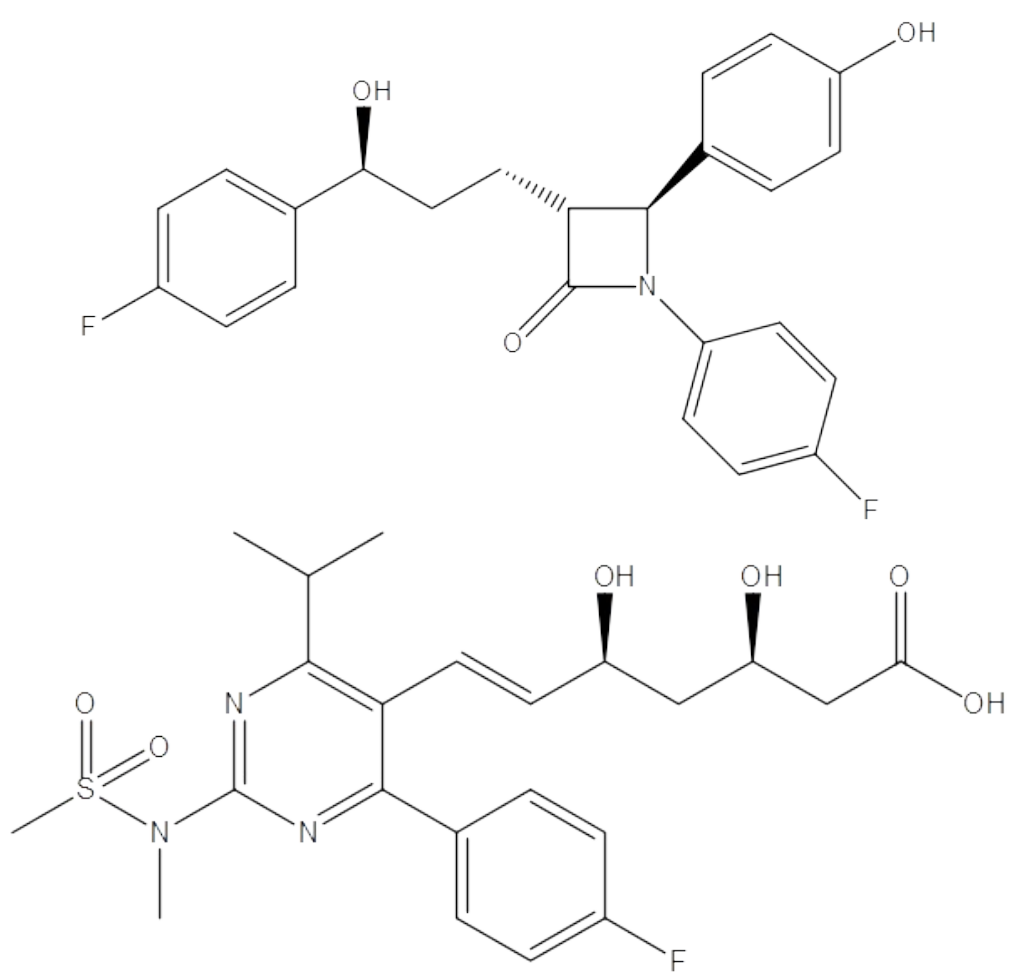

Scheme 1. Structures of Ezetimibe (top) and Rosuvastatin (bottom). 


\section{EXPERIMENTAL}

\section{Chemicals}

We kindly obtained ROS and EZE from NUVOMED İLAÇ SAN. TIC. A.Ş. We received hydrogen peroxide, 0 -phosphoric acid, and microcrystalline cellulose from Sigma-Aldrich (St Louis, MO, USA). We purchased methanol, acetonitrile, sodium hydroxide, and hydrochloric acid, from Merck. To have ultra-pure water, we used Pure Flex water system (ELGA, Wycombe, UK). If not specified, all chemicals are of analytical reagent grade.

\section{Instrumentation}

We utilized the Agilent Hewlett-Packard 1100 HPLC system (Avondale, USA) consisting of DAD variable wavelength detector and data processing, which was supported with B.04.03 version of Chemstation ${ }^{\circledR}$. We used Thermo Scientific Benchtop $\mathrm{pH}$ meter (Orion 3 Star $^{\mathrm{TM}}$ Plus, USA) for the $\mathrm{pH}$ measurements. For the stationary phase, Zorbax SB-C18 $(100 \mathrm{~mm} \times 4.6 \mathrm{~mm}$ and $3.5 \mu \mathrm{m}$ particle size), we purchased from Agilent Technologies (Agilent, USA)). For the preparation of pharmaceuticals, we used a tableting machine (Erweka EP-1, Germany).

\section{MATERIAL AND METHODS}

\section{Chromatographic conditions}

As the stationary phase, we used Zorbax SB-C18 $(100 \mathrm{~mm} \times 4.6 \mathrm{~mm}$ and $3.5 \mu \mathrm{m}$ particle size (Agilent, USA)) column in isocratic mode at $30^{\circ} \mathrm{C}$ and $1.2 \mathrm{~mL} / \mathrm{min}$ flow rate with a mobile phase consisting of water containing $0.1 \%$ $\mathrm{H}_{3} \mathrm{PO}_{4}$ :methanol:acetonitrile $(50: 25: 25 \mathrm{v} / \mathrm{v} / \mathrm{v})$, with an injection volume of $10 \mu \mathrm{L}$. We used $5.0 \mathrm{M} \mathrm{NaOH}$ to adjust the $\mathrm{pH}$ of the mobile phase; we degassed and afterwards filtered the mobile phase. Prior to injections, we pre-conditioned the column for 30 min with the mobile phase. We washed the autosampler needle with mobile phase between each injection. We detected the samples at $242 \mathrm{~nm}$.

\section{Preparation of solutions}

We prepared the stock solutions by dissolving ROS and EZE in methanol and diluted to desired concentrations with the mobile phase. We separated stock solutions of rabbit plasma using the solvent precipitation method. After addition of test solutions to the plasma, we mixed aliquots of $250 \mu \mathrm{L}$ of plasma with $250 \mu \mathrm{L}$ of cold acetonitrile and vortexed to precipitate the proteins. We then removed the precipitated proteins by centrifugation at $10000 \mathrm{rpm}$ for $15 \mathrm{~min}$. We withdrew $50 \mu \mathrm{L}$ aliquots mixed with $950 \mu \mathrm{L}$ mobile phase. We then placed aliquots of the resulting clear supernatants into the HPLC vials. We utilized $\mathrm{KBr}$ solution $0.01 \%(\mathrm{v} / \mathrm{w})$ in water in chromatograms, to have the dead time $\left(t_{0}\right)$.

\section{Formulation and analyzing EZE-ROS tablets}

We prepared tablets using direct compression method. Each tablet contained $10 \mathrm{mg}$ of ROS and EZE as active substances and $230 \mathrm{mg}$ of microcrystalline cellulose as the binder. Prior to compression, we screened granules using $300 \mu \mathrm{m}$ sieve and then thoroughly blended in a mortar with pestle. For the preparation of tablets with an average weight of $250 \mathrm{mg}$, we utilized a single punch-tableting machine armed with flat-faced punches with a die, whose diameter was $11 \mathrm{~mm}$.

\section{System suitability test studies and validation of the method}

We tested HPLC system using with USP criteria related to system suitability like capacity factor (from integrator), symmetry (at $10 \%$ height), tailing factor, and theoretical plate number. Subsequently, we achieved the validation of the proposed method and reported related to $\mathrm{ICH}$ guidelines and USP criteria (24-27). We injected different concentrations of ROS and EZE to the system to assess the linear range from triplicate injections. Thereafter, we accomplished the area of the detector response versus corresponding concentration to plot calibration graphs. We used least squares linear regression statistical analysis for the regression data analysis. Using the equations of $3.3 \times \mathrm{s} / \mathrm{m}$ and $10 \times \mathrm{s} / \mathrm{m}$, we calculated the limit of detection (LOD) and limit of quantification (LOQ), respectively. In these equations, (s) refers to the standard deviation of response and $(\mathrm{m})$ to the slope of the calibration curve (25-27). We performed precision studies from averages of five measurements that were conducted in the same day and between days from $10 \mu \mathrm{g} / \mathrm{mL}$ for both standard and spiked rabbit serum samples. We confirmed the accuracy of the proposed method by recovery studies, which were performed using a standard addition procedure. We conducted recovery analysis by adding $5 \mu \mathrm{g} / \mathrm{mL}$ standard solutions of ROS and EZE on pharmaceutical dosage form to see the effect of ingredients. We expressed recovery studies in terms of the percent recovery, percent relative standard deviation and bias values. We performed recovery studies separately in mobile phase and serum samples.

According to $\mathrm{ICH}$ recommendations degradation studies consisted in terms of mild and drastic conditions $(24,28)$. For thermal degradation of ROS and EZE, we located solid state of them in an oven at $75{ }^{\circ} \mathrm{C}$ for 3 and 24 hours. We achieved acidic and oxidative degradation of $50 \mu \mathrm{g} / \mathrm{mL}$ ROS and EZE by exposing with hydrochloric acid $(0.5 \mathrm{M} \mathrm{HCl}$ and $1 \mathrm{M}$ $\mathrm{HCl}$ ) and $\mathrm{H}_{2} \mathrm{O}_{2}(33 \%$ and $3 \%)$. We exposed these solutions for 3 hours under stress conditions. For alkaline hydrolysis, we exposed $50 \mu \mathrm{g} / \mathrm{mL}$ ROS and EZE to $0.5 \mathrm{M}$ and $1 \mathrm{M} \mathrm{NaOH}$ for 3 hours. 


\section{RESULTS AND DISCUSSIONS}

\section{Method development}

Prior to the validation studies, we improved the optimization of the HPLC detection parameters such as mobile phase composition in terms of \% amount of $\mathrm{H}_{3} \mathrm{PO}_{4}$, methanol, and acetonitrile and $\mathrm{pH}$; the flow rate and the temperature of the columns, (Data not shown) to have the optimum separation between ROS and EZE. Using Zorbax SB-C18 (100 $\mathrm{mm} \times 4.6 \mathrm{~mm}, 3.5 \mu \mathrm{m}$ particle size) column at 30 ${ }^{\circ} \mathrm{C}$ with the mobile phase composition as water containing $\quad 0.1 \% \quad \mathrm{H}_{3} \mathrm{PO}_{4}$ :methanol:acetonitrile $(50: 25: 25 \mathrm{v} / \mathrm{v} / \mathrm{v})$ at $1.2 \mathrm{~mL} / \mathrm{min}$ flow rate we obtained an acceptable separation.

\section{Parameters of System Suitability Tests}

Prior to the chromatographic analysis we performed system suitability tests related to USP criteria (25$27)$. We examined capacity factor $(>2)$, symmetry at $10 \%$ height $(<2)$, USP tailing $(<2)$, theoretical plate number $(>2000)$, resolution (>1.5) parameters which were all intolerable limits (24, 25). Moreover, the retention time of ROS was 2.80 min and EZE was $4.50 \mathrm{~min}$. We found resolution between ROS and EZE as 10.58 and we calculated selective factor as 1.90 between ROS and EZE. We summarized all the parameters related to system suitability tests in Table 1.

Table 1: Parameters of System Suitability Tests.

\begin{tabular}{cccc}
\hline Parameters & ROS & EZE & $\begin{array}{c}\text { Recommended } \\
\text { Value }\end{array}$ \\
\hline Capacity Factor & 2.05 & 3.90 & $>2$ \\
Selectivity to previous peak & - & 1.90 & $>1$ \\
Resolution to previous peak & - & 10.58 & $>2$ \\
Tailing Factor & 1.21 & 1.17 & $<2$ \\
Symmetry at 10\%height & 1.09 & 1.16 & $<2$ \\
Theoretical number of plates & 6904 & 9358 & $>2000$ \\
\hline
\end{tabular}

\section{Method Validation}

\section{Linearity}

The analytical performance of the method revealed by a linear relationship between ROS and EZE concentrations varying from 0.05 to $25 \mu \mathrm{g} / \mathrm{mL}$ for ROS, and 0.05 to $50 \mu \mathrm{g} / \mathrm{mL}$ for EZE. By means of the linearity equations, we obtained the LOD values as $0.006 \mu \mathrm{g} / \mathrm{mL}$ and $0.008 \mu \mathrm{g} / \mathrm{mL}$ for ROS and EZE, respectively. Readers can also follow Table 2 that, we obtained the calibration curves between 0.25-10 $\mu \mathrm{g} / \mathrm{mL}$ for ROS and $0.5-10 \mu \mathrm{g} / \mathrm{mL}$ for EZE in a biological sample, spiked rabbit serum. We reported all statistical assessment of the calibration data in Table 2 and we presented chromatograms of increasing concentrations of EZE and ROS in Figure 1 in mobile phase and in Figure 2 in a biological sample, spiked rabbit serum.

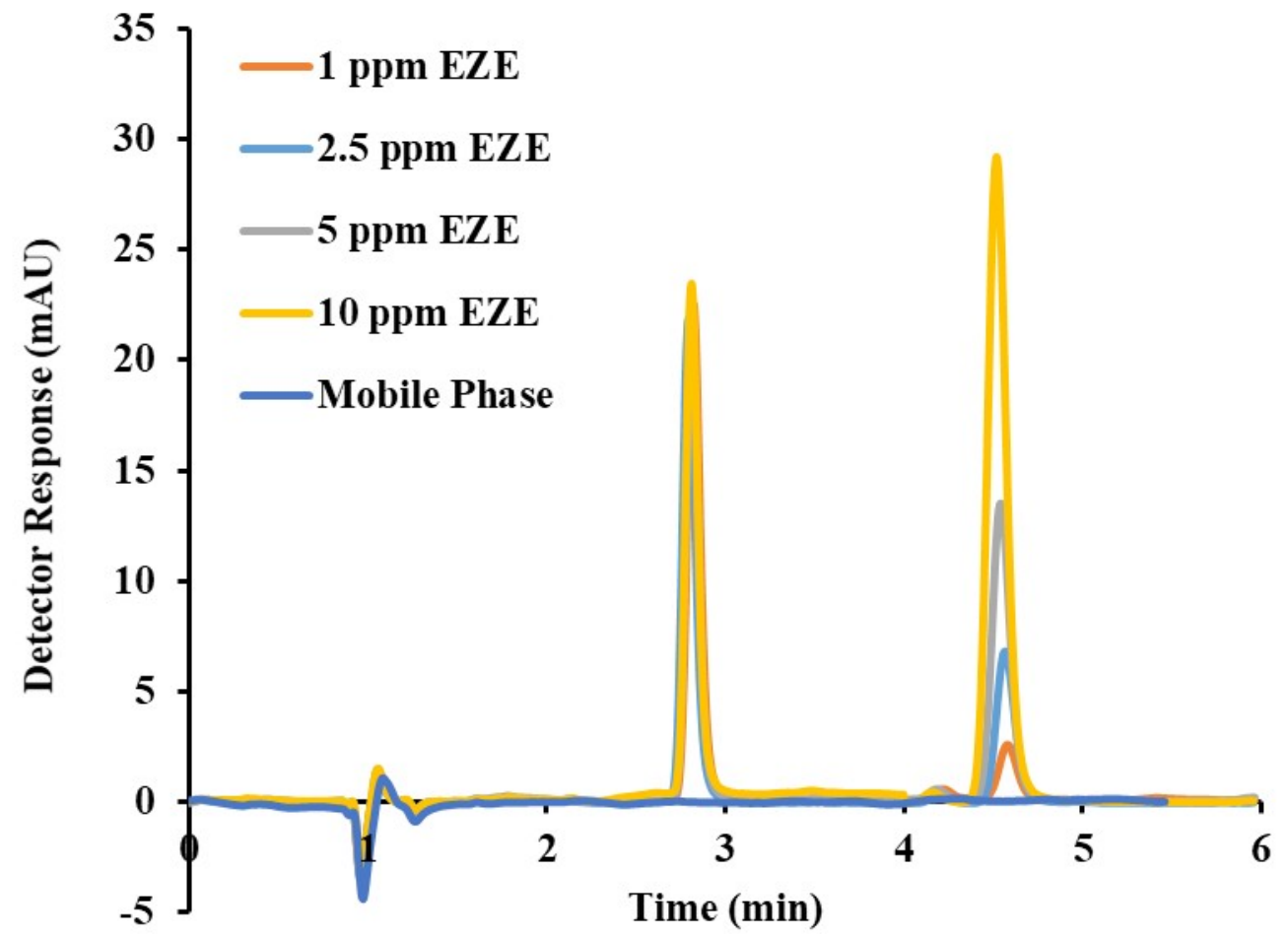




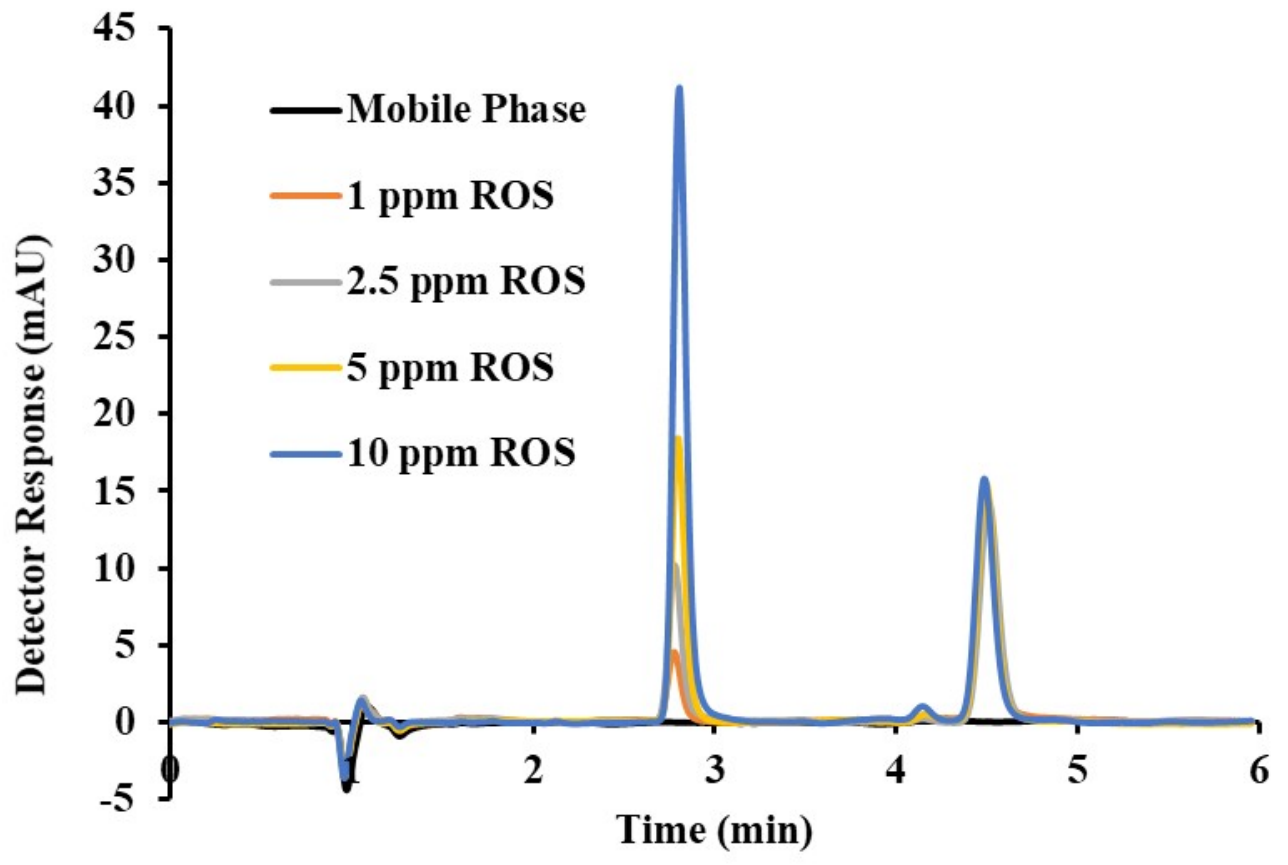

Figure 1: Chromatograms of increasing concentrations of EZE in the presence of $5 \mu \mathrm{g} / \mathrm{mL}$ ROS in $\mathrm{mobile}$ phase (top) and ROS in the presence of $5 \mu \mathrm{g} / \mathrm{mL}$ EZE in mobile phase (bottom).

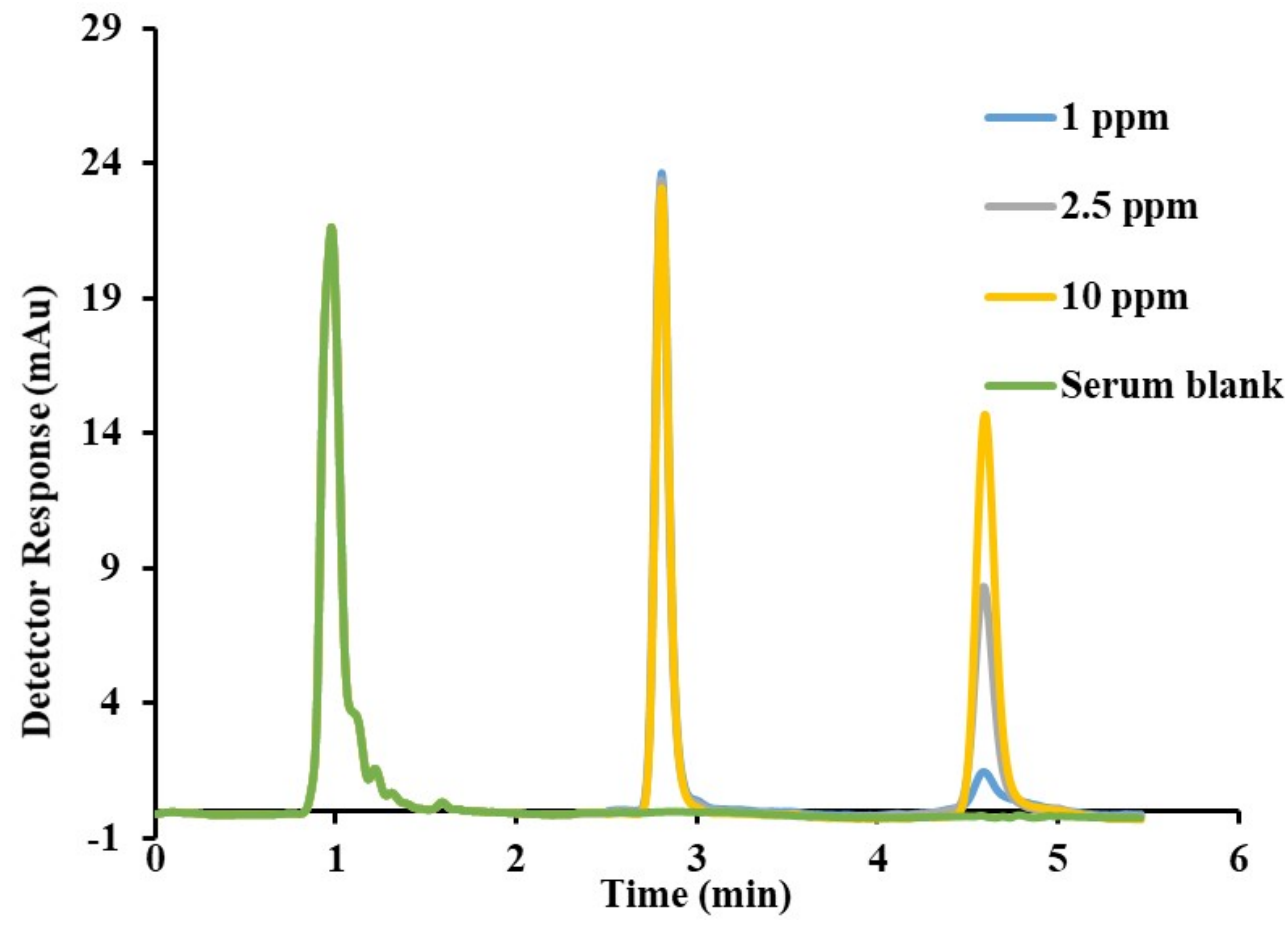




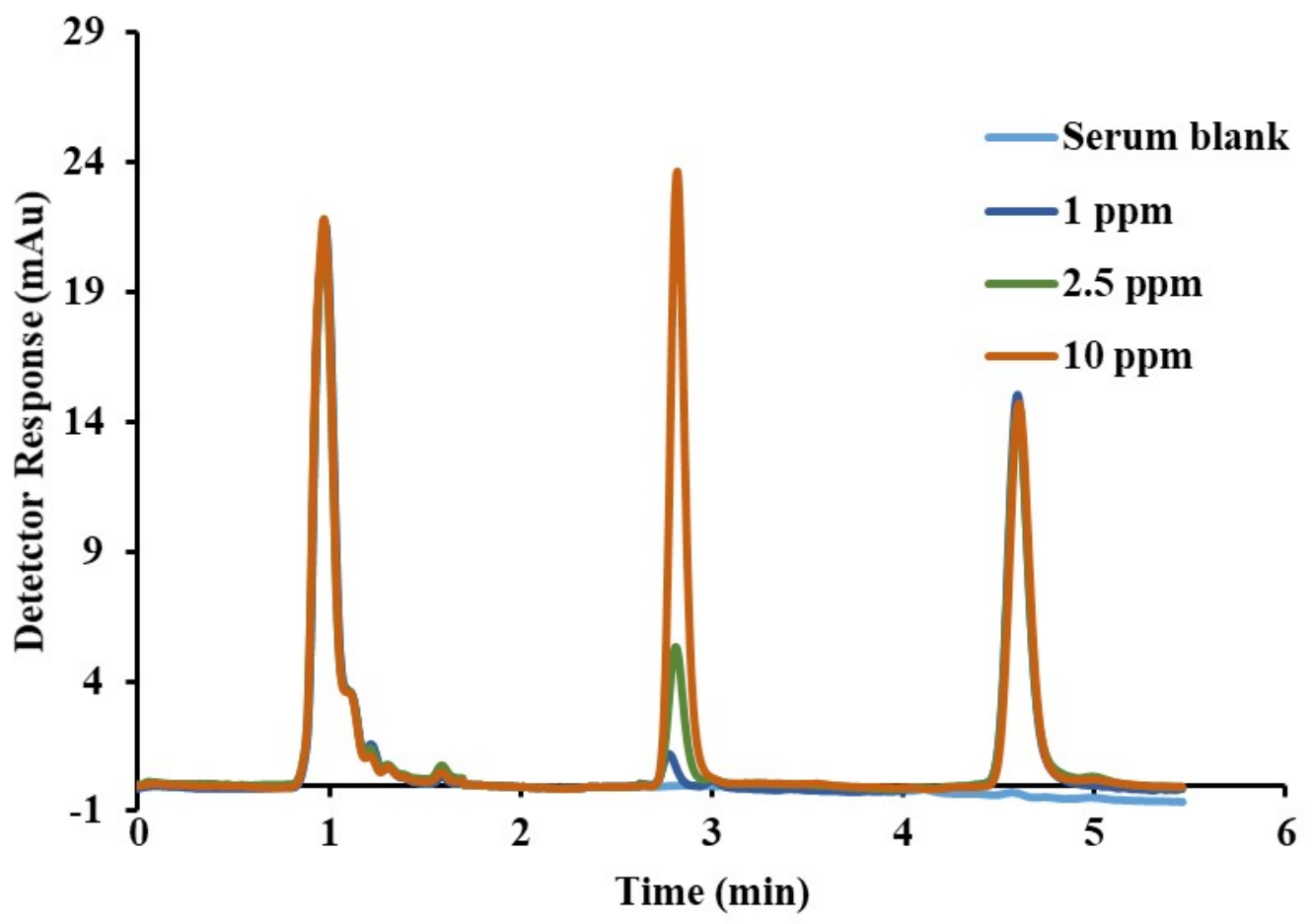

Figure 2: Chromatograms of increasing concentrations of EZE in the presence of $5 \mu \mathrm{g} / \mathrm{mL}$ ROS (top) and ROS in the presence of $10 \mu \mathrm{g} / \mathrm{mL}$ EZE (bottom) in spiked rabbit serum samples.

\section{Precision: Repeatability studies}

To have a precise method, we followed in day and between days repeatability studies and gave in terms of RSD \%. It can be resulted from Table 2 that, low values of RSD \% values indicate that the developed method is precise for the assay of both standard solutions and spiked rabbit serum samples of ROS and EZE.

Table 2: Statistical evaluation of the calibration data.

\begin{tabular}{ccccc}
\hline & \multicolumn{2}{c}{ Mobile Phase } & \multicolumn{2}{c}{ Rabbit Serum } \\
\hline Compounds & ROS & EZE & ROS & EZE \\
\hline Linearity range $(\mu \mathrm{g} / \mathrm{mL})$ & $0.05-25$ & $0.05-50$ & $0.25-10$ & $0.5-10$ \\
Slope $(\mathrm{mAU} / \mu \mathrm{g} . \mathrm{mL})$ & 23.386 & 23.270 & 24.412 & 20.916 \\
Intercept $(\mathrm{mAU})$ & -3.362 & -6.521 & 7.240 & 15.727 \\
Correlation coefficient & 0.999 & 0.999 & 0.999 & 0.999 \\
LOD $(\mu \mathrm{g} / \mathrm{mL})$ & 0.006 & 0.008 & 0.054 & 0.010 \\
LOQ $(\mu \mathrm{g} / \mathrm{mL})$ & 0.018 & 0.025 & 0.164 & 0.028 \\
Within day Repeatability $(\mathrm{RSD} \%)$ & 0.746 & 0.209 & 0.425 & 0.451 \\
Between day Repeatability $(\mathrm{RSD} \%)$ & 0.724 & 0.482 & 0.513 & 0.831 \\
\hline
\end{tabular}

${ }^{a}$ Each value is the mean of five experiments.

\section{Specificity: Degradation studies}

We accomplished that degradation studies for 50 $\mu \mathrm{g} / \mathrm{mL}$ ROS and EZE for specificity of the method. We designed degradation experiments at mild and drastic conditions with exposure to acidic and alkaline hydrolysis, hydrogen peroxide, UV, and heat. We presented related results in Table 3 . It can be resulted that, since we found the degradation percentage more than 90 in heating and UV exposure, the method and the drug active compounds especially ROS are very sensitive to heating and UV exposure. 
Table 3: The results of hydrolytic, oxidizing, thermal, and photolytic stressed under drastic and mild conditions of ROS and EZE using developed HPLC method.

\begin{tabular}{|c|c|c|c|}
\hline & Response Stress Conditions & $\begin{array}{l}\text { Degradation } \\
\text { of ROS\% }\end{array}$ & $\begin{array}{l}\text { Degradation } \\
\text { of EZE\% }\end{array}$ \\
\hline \multirow{5}{*}{$\begin{array}{c}\text { Drastic } \\
\text { Conditions }\end{array}$} & $\mathrm{HCl}(1 \mathrm{M})$ & 85.63 & 25.90 \\
\hline & $\mathrm{NaOH}(1 \mathrm{M})$ & 75.25 & 35.98 \\
\hline & $\mathrm{H}_{2} \mathrm{O}_{2}(30 \%)$ & 77.79 & 36.02 \\
\hline & Thermal (24 hours at $75^{\circ} \mathrm{C}$ ) & 96.72 & 57.39 \\
\hline & $\begin{array}{c}\text { UV light exposure } \\
(24 \text { hours at } 254 \mathrm{~nm})\end{array}$ & 97.92 & 56.56 \\
\hline \multirow{5}{*}{$\begin{array}{c}\text { Mild } \\
\text { Conditions }\end{array}$} & $\mathrm{HCl}(0.5 \mathrm{M})$ & 70.82 & 15.90 \\
\hline & $\mathrm{NaOH}(0.5 \mathrm{M})$ & 52.56 & 23.19 \\
\hline & $\mathrm{H}_{2} \mathrm{O}_{2}(3 \%)$ & 44.52 & 22.40 \\
\hline & Thermal ( 3 hours at $75^{\circ} \mathrm{C}$ ) & 96.94 & 51.83 \\
\hline & $\begin{array}{l}\text { UV light exposure } \\
\text { (3 hours at } 254 \mathrm{~nm})\end{array}$ & 97.63 & 52.81 \\
\hline
\end{tabular}

\section{Accuracy: Pharmaceutical analysis and recovery studies}

We realized the determination of ROS and EZE as pharmaceutical dosage form (see Figure 3) and recoveries from the pharmaceutical dosage form and rabbit serum samples to conduct accuracy studies. In account of that, we used the related obtained equations for the calibration curves for the simultaneous determination of ROS and EZE. We added known amounts of standard solutions $(5 \mu \mathrm{g} /$ $\mathrm{mL}$ ) over pharmaceutical dosage form samples and serum samples for the recovery studies. The results of recovery \%, RSD \% and Bias \% were shown in the Table 4 . We found mean of the spike recoveries between $99-101 \%$ for tablet and serum samples that specifies a tolerable accuracy of the method. Accordingly, it can be noticed that the developed method was not affected from the possible interferences in the tablet and rabbit serum.

As a result, we herein suggested a powerful, suitable, and valuable method for analysis of ROS and EZE with fully validated conditions. Since in our method, the organic solvent consumption is only 3 $\mathrm{mL}$ per injection and analysis time is $5 \mathrm{~min}$, greener approach (29-32) shorter analysis time (29, 30) was investigated when we compare the results within the literature.

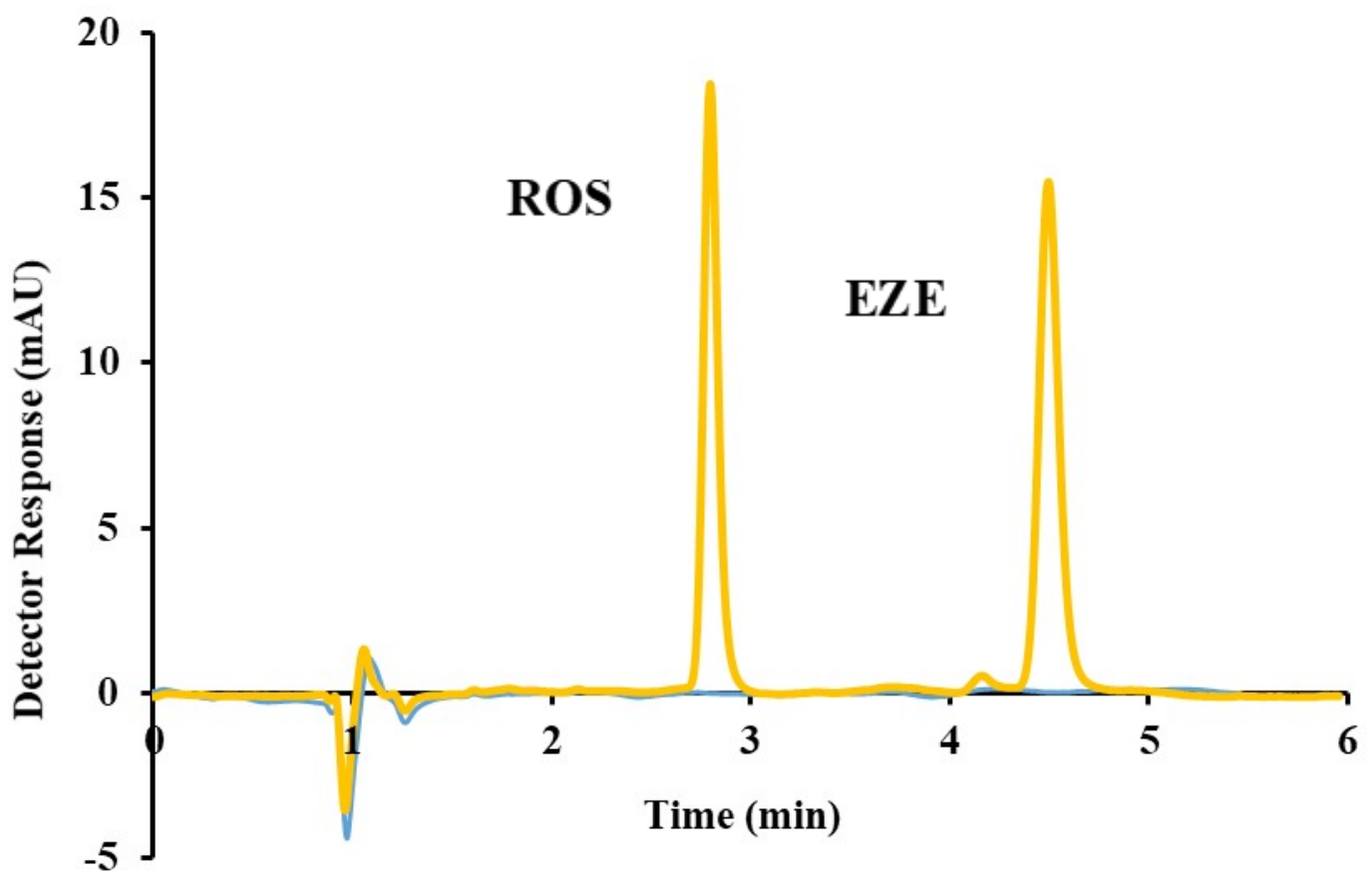

Figure 3: The chromatogram of $5 \mu \mathrm{g} / \mathrm{mL}$ Rosuvastatin and Ezetimibe from prepared tablet formulation. 
Table 4: Results of tablet and recovery analysis.

\begin{tabular}{|c|c|c|c|c|}
\hline & \multicolumn{2}{|c|}{ Mobile Phase } & \multicolumn{2}{|c|}{ Rabbit Serum } \\
\hline & ROS & EZE & ROS & EZE \\
\hline Label Prepared (mg) & 10.00 & 10.00 & - & - \\
\hline Found & 10.06 & 10.07 & - & - \\
\hline RSD (\%) & 0.95 & 0.49 & - & - \\
\hline Bias (\%) & -0.63 & -0.71 & - & - \\
\hline Added (mg) & 5.00 & 5.00 & 5.00 & 5.00 \\
\hline Found $^{\mathrm{a}}(\mathrm{mg})$ & 5.04 & 5.05 & 4.98 & 5.01 \\
\hline Recovery (\%) & 100.80 & 101.00 & 99.60 & 100.20 \\
\hline RSD of recovery (\%) & 0.82 & 0.25 & 0.93 & 0.85 \\
\hline Bias (\%) & -0.80 & -1.00 & 0.40 & -0.20 \\
\hline
\end{tabular}

aEach value is the mean of five experiments.

\section{CONCLUSIONS}

In this study, we achieved a simultaneous determination of ROS and EZE with optimization and validation studies via a selective, sensitive, precise, and accurate HPLC method. The system suitability test parameters were also reports as capacity factor (ROS:2.05; EZE:3.90), symmetry at $10 \%$ height (ROS:1.09; EZE:1.16), USP tailing (ROS:1.21; EZE:1.17), theoretical plate number (ROS:6904; EZE:9358), resolution (EZE:10.58), and selectivity (EZE:1.90) parameters. After having the optimum conditions for separation such as Zorbax SB-C18 (100 mm x $4.6 \mathrm{~mm}, 3.5 \mu \mathrm{m}$ particle size) column at $30{ }^{\circ} \mathrm{C}$ with a mobile phase that has a composition as water containing $0.1 \% \mathrm{H}_{3} \mathrm{PO}_{4}$ :methanol:acetonitrile $(50: 25: 25 \mathrm{v} / \mathrm{v} / \mathrm{v})$ at $1.2 \mathrm{~mL} / \mathrm{min}$ flow rate; we followed the full validation parameters. In order to show that the method is suitable for the detection of ROS and EZE, we further achieved the detection of ROS- and EZE-spiked rabbit serum samples. Furthermore, we also accomplished degradation studies and we utilized the stability indicating method to analyze ROS and EZE in spiked rabbit serum samples.

\section{ACKNOWLEDGEMENT}

Sevinc Kurbanoglu and Ozgur Esim acknowledge the support given by Ankara University BAP 17B0237002.

\section{REFERENCES}

1. Schultheis A. Hypercholesterolemia: prevention, detection and management. Nurse Pract. 1990;15:40-6.

2. Ross R. The Pathogenesis of Atherosclerosis - An Update. Vol. 314, New England Journal of Medicine. 1986. p. 488-500.

3. Ornish D, Brown SE, Billings JH, Scherwitz LW, Armstrong WT, Ports TA, et al. Can lifestyle changes reverse coronary heart disease?. The
Lifestyle Heart Trial. Lancet. 1990 Jul $21 ; 336(8708): 129-33$.

4. Ulbricht TLV, Southgate DAT. Coronary heart disease: seven dietary factors. Lancet. 1991 Oct $19 ; 338(8773)$ : 985-92.

5. Chapman MJ, McTaggart F. Optimizing the pharmacology of statins: Characteristics of rosuvastatin. In: Atherosclerosis Supplements. 2002. p. 33-7.

6. Kosoglou T, Statkevich P, Yang B, Suresh R, Zhu Y, Boutros T, et al. Pharmacodynamic interaction between ezetimibe and rosuvastatin. Curr Med Res Opin. 2004;20(8):1185-95.

7. Gagné C, Bays HE, Weiss SR, Mata P, Quinto $K$, Melino $M$, et al. Efficacy and safety of ezetimibe added to ongoing statin therapy for treatment of patients with primary hypercholesterolemia. Am J Cardiol. 2002;90(10):1084-91.

8. Bays HE, Moore PB, Drehobl MA, Rosenblatt $S$, Toth PD, Dujovne CA, et al. Effectiveness and tolerability of ezetimibe in patients with primary hypercholesterolemia: pooled analysis of two phase II studies. Clin Ther. 2001;23(8):1209-30.

9. Nutescu EA, Shapiro NL. Ezetimibe: A Selective Cholesterol Absorption Inhibitor. Pharmacotherapy. 2003;23(11):1463-74.

10. McTaggart F. Comparative pharmacology of rosuvastatin. In: Atherosclerosis Supplements. Elsevier Ireland Ltd; 2003. p. 9-14.

11. McTaggart F, Buckett $L$, Davidson R, Holdgate G, McCormick A, Schneck D, et al. Preclinical and clinical pharmacology of rosuvastatin, a new 3-hydroxy-3-methylglutaryl coenzyme A reductase inhibitor. In: American Journal of Cardiology. Elsevier Inc.; 2001. p. 28-32.

12. Stein EA. Management of 
hypercholesterolemia. Approach to diet and drug therapy. Am J Med. 1989;87(SUPPL. 4).

13. Davidson $\mathrm{MH}$. Rosuvastatin: A highly efficacious statin for the treatment of dyslipidaemia. Expert Opin Investig Drugs. 2002;11(1):125-32.

14. Shah Y, Iqbal Z, Ahmad L, Khan A, Khan MI, Nazir $S$, et al. Simultaneous determination of rosuvastatin and atorvastatin in human serum using RP-HPLC/UV detection: Method development, validation and optimization of various experimental parameters. J Chromatogr B Anal Technol Biomed Life Sci. 2011 Mar 15;879(9-10):557-63.

15. Nasir F, Iqbal Z, Khan A, Ahmad L, Shah Y, Khan $A Z$, et al. Simultaneous determination of timolol maleate, rosuvastatin calcium and diclofenac sodium in pharmaceuticals and physiological fluids using HPLC-UV. J Chromatogr B Anal Technol Biomed Life Sci. 2011;879(30):3434-43.

16. Gomes FP, Garcia PL, Porto Alves JM, Singh AK, Kedor-Hackmann ERM, Santoro MIRM. Development and validation of stability-indicating hplc methods for quantitative determination of pravastatin, fluvastatin, atorvastatin, and rosuvastatin in pharmaceuticals. Anal Lett. 2009;42(12):1784-804.

17. Sultana N, Arayne MS, Shah SN, Shafi N, Naveed S. Simultaneous determination of prazosin, atorvastatin, rosuvastatin and simvastatin in API, dosage formulations and human serum by RP-HPLC. J Chinese Chem Soc. 2010;57(6):1286-92.

18. DeGorter MK, Tirona RG, Schwarz UI, Choi YH, Dresser GK, Suskin N, et al. Clinical and pharmacogenetic predictors of circulating atorvastatin and rosuvastatin concentrations in routine clinical care. Circ Cardiovasc Genet. $2013 ; 6(4): 400-8$.

19. Patel J, Sheehan V, Gurk-Turner C. Ezetimibe (Zetia): A New Type of Lipid-Lowering Agent. Baylor Univ Med Cent Proc. 2003;16(3):3548.

20. Kawashiri MA, Nohara A, Noguchi T, Tada H, Nakanishi C, Mori $M$, et al. Efficacy and safety of coadministration of rosuvastatin, ezetimibe, and colestimide in heterozygous familial hypercholesterolemia. Am J Cardiol. 2012;109(3):364-9.

21. Ballantyne CM, Weiss R, Moccetti T, Vogt A, Eber B, Sosef F, et al. Efficacy and Safety of Rosuvastatin $40 \mathrm{mg}$ Alone or in Combination With Ezetimibe in Patients at High Risk of Cardiovascular Disease (Results from the EXPLORER Study). Am J Cardiol. 2007;99(5):673-80.
22. Yang YJ, Lee SH, Kim BS, Cho YK, Cho HJ, Cho KI, et al. Combination Therapy of Rosuvastatin and Ezetimibe in Patients with High Cardiovascular Risk. Clin Ther. 2017 Jan 1;39(1):107-17.

23. Swartz ME, Murphy B. New frontiers in chromatography. Am Lab. 2005;37(3):22-7.

24. Borman P, Elder D. Q2(R1) Validation of Analytical Procedures. In: ICH Quality Guidelines. John Wiley \& Sons, Inc.; 2017. p. 127-66.

25. Swartz ME, Krull IS. Analytical Method Development and Validation. 1997;3(4):96.

26. The USP 40. The United States

Pharmacopeia, The Official Compendia of Standards. MD, Rockville, USA.; 2017.

27. Gumustas M, Kurbanoglu S, Uslu B, Ozkan

SA. UPLC versus HPLC on drug analysis: Advantageous, applications and their validation parameters. Chromatographia. 2013;76(2122):1365-427.

28. Blessy M, Patel RD, Prajapati PN, Agrawal YK. Development of forced degradation and stability indicating studies of drugs - A review. J Pharm Anal. 2014;4(3):159-65.

29. Swathi Sri D, Hemant Kumar T, Vara Prasada Rao K, Srinivasa Rao Y. Validated RP-HPLC method for simultaneous determination of Rosuvastatin Calcium and Ezetimibe in pharmaceutical dosage form. Int J Pharm Pharm Sci. 2015;7(4):209-13.

30. Gajjar A, Gajjar AK, Shah VD. Development and Validation of a Stability-Indicating ReversedPhase HPLC Method for Simultaneous Estimation of Rosuvastatin and Ezetimibe from Their Combination Dosage Forms Rational Drug Designing on Glycogen Synthase Kinase-3 beta View project Developme. Eurasian J Anal Chem. 2010;5(3):280-98.

31. Mukthinuthalapati MA, Bukkapatnam V, Bandaru SPK. Stability indicating liquid chromatographic method for the simultaneous determination of rosuvastatin and ezetimibe in pharmaceutical formulations. Adv Pharm Bull. 2014;4(4):405-11.

32. Varghese SJ, Ravi TK. Determination of rosuvastatin and ezetimibe in a combined tablet dosage form using high-performance column liquid chromatography and high-performance thin-layer chromatography. J AOAC Int. 2010;93(4):1222-7. 
